SHORT REPORT

\title{
High tolerance for oral galactose in classical galactosaemia: dietary implications
}

\author{
A M Bosch, H D Bakker, L J M de B Wenniger-Prick, R J A Wanders, F A Wijburg
}

Arch Dis Child 2004;89:1034-1036. doi: 10.1136/adc.2003.037671

\begin{abstract}
Aim: To study the relevance of restricting the exogenous intake of small amounts of galactose, such as from fruit and vegetables, in patients with classical galactosaemia. Methods: For a period of six weeks, increasing doses of oral galactose to a maximum of $600 \mathrm{mg}$ per day, were added to a very strict galactose restricted diet in three adolescent patients homozygous for the Q188R mutation. During the study, physical examination, including an extended ophthalmic examination, and laboratory studies were performed on a weekly basis.

Results: No significant change in any of the studied clinical or biochemical parameters was observed.

Conclusions: These findings provide further evidence that attempts to exclude trace amounts of galactose from the diet are not justified. Once the diet is made more liberal, a long term follow up study will be necessary.
\end{abstract}

${ }^{1}$ assical galactosaemia is an autosomal recessive disorder of galactose metabolism caused by a deficiency of the enzyme galactose-1-phosphate uridyltransferase (GALT; EC 2.7.12). Although dietary galactose restriction is life saving, ${ }^{1}$ even a strict dietary treatment does not prevent all patients from developing late complications, such as mild psychomotor retardation, speech disorders, and hypergonadotrophic hypogonadism. ${ }^{2-7}$ Endogenous production of galactose, amounting to 1 gram per day in adults, has been suggested to be a major cause of the late complications. ${ }^{8}$. There are controversies concerning the daily allowance of galactose during long term treatment. Many European metabolic centres, including those in the Netherlands, recommend a very strict diet, with restriction of galactose containing fruits and vegetables, thus further complicating the life of patients with galactosaemia. Other centres, for example those in the UK, are more liberal, advising a lactosefree diet. ${ }^{10}$ In view of the high endogenous galactose production, it is questionable whether such a severe restriction of galactose intake is relevant. We performed a study in adolescent galactosaemic patients, introducing increasing supplementations of oral galactose to a severely restricted diet, in order to try to determine the tolerance for exogenous galactose in these patients.

\section{METHODS \\ Patients}

This study was approved by the Medical Ethical Committee of the Academic Medical Centre in Amsterdam. Patients were included after informed consent was obtained from the patients and their parents. Three patients, homozygous for the Q188R mutation and all on a galactose restricted diet since the time of diagnosis, participated in the study. Patient 1 was a 15 year old female weighing $43 \mathrm{~kg}$. Patient 2 was an 18 year old female weighing $65 \mathrm{~kg}$, and patient 3 was her 16 year old brother who weighed $69 \mathrm{~kg}$. During the study period, patient 2 received uninterrupted oral contraceptive medication. No other galactose containing medication was used during this study.

\section{Diet}

The patients consulted a specialised dietician on a weekly basis. During weeks 1 and 2 of the study, patients remained on their regular galactose restricted diet. From week 3 to week 10 of the study, all three studied patients were put on a very strict galactose restricted diet. Three-day dietary records were maintained and assessed for the daily consumption of galactose as estimated by the list of Gross and Acosta. ${ }^{11}$

\section{Galactose supplementation}

From week 5 of the study, the patients received an oral dose of galactose, administered in $100 \mathrm{mg}$ capsules, in two daily doses taken with meals. During weeks 5 and 6 of the study they received a daily dose of $200 \mathrm{mg}$ galactose ( $100 \mathrm{mg}$ twice a day), during weeks 7 and 8 a dose of $400 \mathrm{mg}$ galactose (200 mg twice a day), and during and weeks 9 and 10 a dose of $600 \mathrm{mg}$ (300 mg twice a day).

\section{Physical examination}

Physical examination, including ophthalmic examination with assessment of visual acuity and refraction, slit lamp examination of the anterior segment, and indirect fundoscopy with dilated pupils, was performed on a weekly basis before and during the galactose supplementation, and three weeks after the last dose of oral galactose. In addition photographs of the lens were taken at the onset, halfway point, and at the end of the study.

\section{Biochemical follow up}

All laboratory studies were performed before galactose administration, on a weekly basis at the beginning of each new study week during the period of galactose supplementation, and twice after returning to the regular diet. Evaluated were plasma aspartate aminotransferase, alanine aminotransferase, bilirubin, alkaline phosphatase, and gamma-glutaryl-transpeptidase, and urine protein, electrolytes, glucose, calcium, phosphate, and magnesium. The effects of galactose ingestion on the specific parameters generally used in the follow up of galactosaemic patients, red cell galactose-1-phosphate, and urinary galactitol, were assessed weekly and were measured as follows. To measure the red cell galactose-1-phosphate an aliquot of washed erythrocytes was taken; protein was denaturated by heating the sample for five minutes in a boiling waterbath. After centrifugation the supernatant was taken and galactose-1-phosphate was measured spectrophotometrically using alkaline phosphatase to convert galactose-1-phosphate into 3-galactose plus phosphate. The released galactose is measured with galactose dehydrogenase under the formation of NADH which can be 
measured at $340 \mathrm{~nm}$. Urine galactitol was measured in a single portion by gas chromatography using the trifluoroacetyl derivatives after treatment with o-ethoxyamine.

\section{RESULTS}

Diet

The total daily dietary galactose intake, as determined by three-day assessment, was $22 \mathrm{mg}, 17 \mathrm{mg}$, and $18 \mathrm{mg}$ of galactose during the patients' usual galactose restricted diet and $11 \mathrm{mg}, 11 \mathrm{mg}$, and $15 \mathrm{mg}$ of galactose during the period of the very strict galactose restricted diet in patients 1,2 , and 3 respectively. By taking contraceptive medication patient 2 ingested an additional $31 \mathrm{mg}$ of galactose daily.

\section{Physical examination}

During the study no adverse events were reported by the patients. Blood pressures and body weights showed normal variation during the study. On physical examination no abnormalities, especially no ophthalmologic abnormalities, were found.

\section{Biochemical examination}

During the study the weekly tests on blood and urine showed no abnormalities. The concentrations of urinary galactitol excretion (fig 1) and red cell galactose-1-phosphate (fig 2) varied during the study, not correlating with the galactose supplements. All but one red cell galactose-1-phosphate values remained below the upper limit of the recommended range $(0.58 \mu \mathrm{mol} / \mathrm{g} \mathrm{Hb})$ as used for the dietary control of Dutch galactosaemia patients. In patient 2 one unexpected high value of $0.80 \mu \mathrm{mol} / \mathrm{g} \mathrm{Hb}$ was measured one week after returning to her normal diet (fig 2). When measured three weeks later the red cell galactose-1-phosphate level had returned to a low value of $0.38 \mu \mathrm{mol} / \mathrm{g} \mathrm{Hb}$.

\section{DISCUSSION}

The advised diet for patients with classical galactosaemia in the Netherlands is a lactose free diet with restrictions in the intake of fruits and vegetables. However, the precise dietary recommendations vary between European countries.

Important is the strong contrast between the exogenous intake of galactose in our patients of 17-22 mg per day on the one hand, and the endogenous production of galactose in these patients of 640-1027 mg per day, as estimated by using the data of Ning and colleagues, on the other hand. In addition, even a lactose-free diet, enriched in galactose-rich fruit and vegetables did not result in a daily galactose intake exceeding $45.2 \mathrm{mg}^{12}$ These data suggest that the reduction of the daily



Figure 1 Urinary galactitol values of patients 1, 2, and 3 during the study.

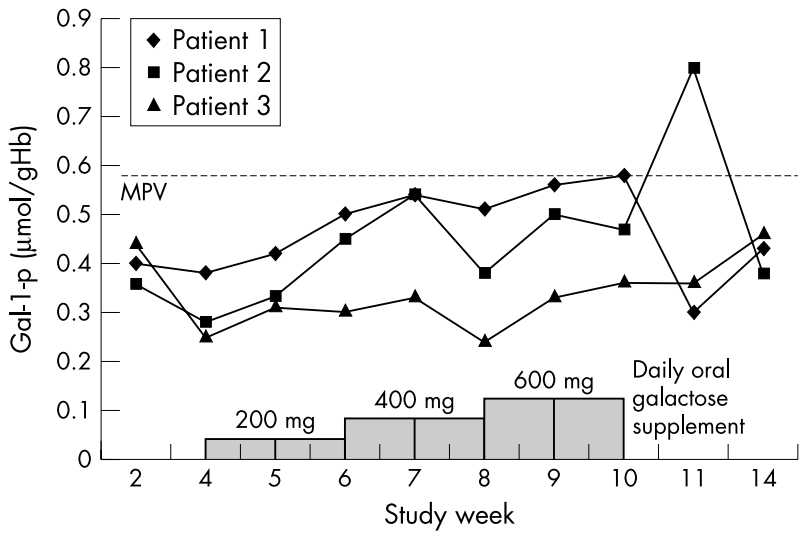

Figure 2 Red cell galactose-1-phosphate values of patients 1, 2, and 3 during the study. MPV, maximum permissible value.

dietary galactose intake by reducing fruit and vegetables is negligible. Indeed, our study showed that supplementation of galactose during a period of six weeks up to a maximum of $600 \mathrm{mg}$ per day did not result in any physical, ophthalmological, or biochemical abnormalities. The one high red blood cell galactose-1-phosphate value, as observed in patient 2 one week after the period of galactose supplementation, was due to a dietary error, with ingestion of cows' milk two days earlier. As $600 \mathrm{mg}$ of galactose equals the amount of galactose in $7 \mathrm{~kg}$ of apples, $2.5 \mathrm{~kg}$ of tomatoes, or $12 \mathrm{~kg}$ of peas, our results suggest that dietary restriction of these products is not of clinical importance. Our findings are supported by the absence of an increase of galactose-1-phosphate in Australian patients during six months following the introduction of a less restricted diet. ${ }^{13}$ Finally, in the United Kingdom, where current advice is that fruit and vegetables need not be eliminated from the diet, there are no reports of an increased incidence of cataracts or liver disease. It may well be that age plays a crucial part in determining susceptibility to galactosaemia as a recent paper showed a very good outcome in an adult woman with classical galactosaemia whose diet was discontinued when she was 3 years old..$^{14}$

Our study provides data based on short term follow up in just three patients. Nevertheless, the findings support the view that there is no need to restrict the intake of fruit and vegetables in patients with galactosaemia. However, once the diet has been made more liberal in our country, a long term follow up study, including physical, biochemical, and psychometric assessments, will be necessary.

Patients with classical galactosaemia are usually monitored by regular measurements of their red blood cell galactose-1phosphate and/or urinary galactitol excretion. As our study revealed that the levels of these metabolites do not significantly increase with a daily galactose intake up to $600 \mathrm{mg}$, we feel that the value of these tests in the regular follow up of patients with classical galactosaemia is as an indicator of serious non-adherence to the diet.

\section{Authors' affiliations}

A M Bosch, H D Bakker, L J M de B Wenniger-Prick, R J A Wanders, F A Wijburg, Academic Medical Centre, University of Amsterdam, Amsterdam, Netherlands

No reprints available

Correspondence to: Dr F A Wiiburg, Paediatrician Metabolic Diseases, Academic Medical Center, University of Amsterdam, Department of Pediatrics (G8-205), PO Box 22660, 1100 DD Amsterdam, Netherlands; F.A.Wijburg@amc.uva.nl

Accepted 11 February 2004 


\section{REFERENCES}

1 Holton JB, Walter JH, Tyfield LA. Galactosemia. In: Scriver CR, Beaudet AL, Sly WS, et al. The metabolic and molecular basis of inherited disease. New York: McGraw-Hill, 2001:1553-83.

2 Gibson JB. Gonadal function in galactosemics and in galactose-intoxicated animals. Eur J Pediatr 1995;154(suppl 2):s14-20.

3 Kaufman FR, McBride-Chang C, Manis FR, et al. Cognitive functioning, neurologic status and brain imaging in classic galactosemia. Eur J Pediatr 1995; 154(suppl 2):s2-5.

4 Nelson D. Verbal dyspraxia in children with galactosemia. Eur J Pediatr 1995; 154(suppl 2):s6-7.

5 Schweitzer S, Shin Y, Jacobs C, et al. Long-term outcome in 134 patients with galactosemia. Eur J Paediatr 1993;152:36-43.

6 Segal S. Galactosemia today: the enigma and the challenge. J Inher Metab Dis 1998;21:445-71.

7 Waggoner DD, Buist NRM, Donnell GN. Long-term prognosis in galactosemia: results of a survey of 350 cases. J Inher Metab Dis 1990;13:802-18.
8 Berry GT, Nissim I, Lin Z, et al. Endogenous synthesis of galactose in normal men and patients with hereditary galactosemia. Lance 1995;346: 1073-4

9 Ning C, Fenn PT, Blair IA, et al. Apparent galactose appearance rate in human galactosemia based on plasma [13C] galactose isotopic enrichment. Mol Genet Metab 2000;70:261-71.

10 Walter JH, Collins JE, Leonard JV. Recommendations for the management of galactosemia. Arch Dis Child 1999;80:93-6.

11 Gross KC, Acosta PB. Fruit and vegetables are a source of galactose: implications of planning the diets of patients with galactosemia. J Inher Metab Dis 1991;14:253-8

12 Berry GT, Palmieri M, Gross KC, et al. The effect of fruit and vegetables on urinary galactitol excretion in galactose-1-phosphate uridyltransferase deficiency. J Inher Metab Dis 1993;16:91-100.

13 Thompson SM, Netting MJ, Jerath S, et al. Effect of a less restricted diet in galactosemia. J Inher Metab Dis 2003;26(suppl 2):214.

14 Lee PJ, Lilburn M, Wendel U, et al. A woman with untreated galactosaemia. Lancet 2003;362:446.
HEY- You maY BE ABLE

to EAT MORE VEGETABLES!

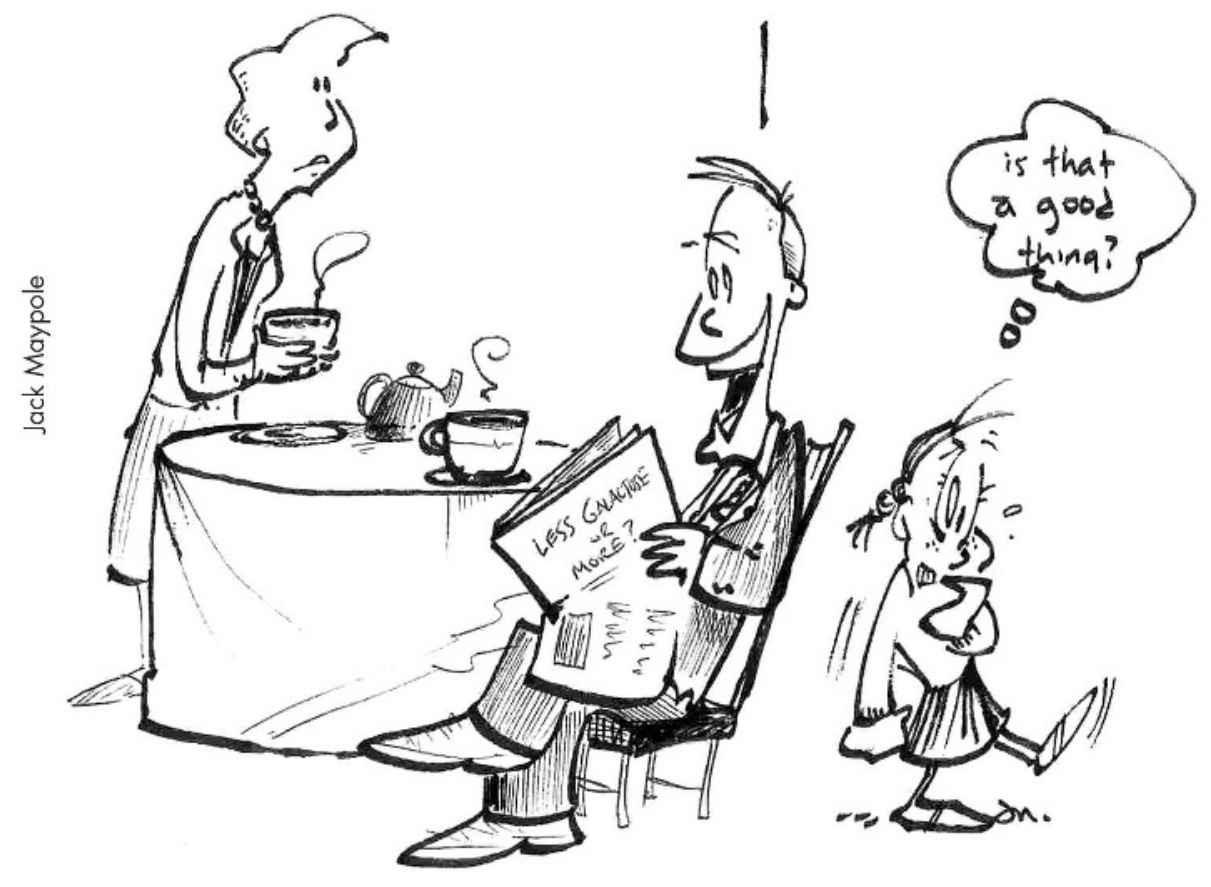

